\title{
Effects of Carbon Monoxide Inhalation on Myocardial Infarct Size Following Experimental Coronary Artery Ligation
}

\author{
Souichiro Sekiya, M.D.,* Sadayuki Sato, M.D.,* \\ Hiroshi Yamaguchi, M.D., ${ }^{* *}$ and Kenichi Harumi, M.D.***
}

\section{SUMMARY}

This study was conducted to determine whether or not a low concentration of carboxyhemoglobin influences the extent and severity of myocardial ischemia caused by coronary ligation. In 10 dogs, electrograms were recorded from 6 epicardial electrodes mounted on the anterior surface of the left ventricle and distributed over the area normally perfused by the lighted branch of the left anterior descending coronary artery. The magnitude of ST segment elevation of the 6 sites in each animal was determined for 15 min after ligation. This elevation was used as an index of the presence and severity of myocardial ischemic injury. Ligation alone increased $\Sigma \mathrm{ST}$ elevation, summed from 6 sites, from $2.06 \pm$ $0.34 \mathrm{mV}$ (SEM) to $24.89 \pm 2.14 \mathrm{mV}$ (SEM). Carbon monoxide inhaled prior to ligation increased the severity and extent of ischemic injury and the magnitude of ST segment elevation in the area peripheral to the ischemic area more than did ligation alone. These changes occurred without elevation of heart rate or arterial pressure. It was concluded that a low background concentration of carboxyhemoglobin at the time of ligation increased the extent and severity of myocardial ischemic injury.

\section{Additional Indexing Words:}

Epicardial electrography ST segment elevation $\quad \Sigma \mathrm{ST}$, Myocardial ischemic injury Hypoxia Myoglobin

\footnotetext{
CARBON monoxide (CO) inhalation produces hypoxia as a result of an 1 increase of carboxyhemoglobin (CO-Hb). It is harmful for those tissues with high oxygen demand such as the myocardium. There were some reports of the electrocardiographic changes due to $\mathrm{CO}$ poisoning. Takahashil ${ }^{11}$ re-

From the Departments of Physiology,* Public Health,** School of Medicinc, Showa University, Tokyo and Division of Cardiology,*** Showa University, Fujigaoka Hospital, Yokohama.

Present address for reprint: Souichiro Sekiya, M.D., Division of Cardiology, Showa University, Fujigaoka Hospital, 1-30 Fujigaoka, Midori-ku, Yokohama 227, Japan.

Received for publication December 7, 1981.

Manuscript revised August 2, 1982.
} 
ported that gross electrocardiographic changes were rarely observed until the blood level of $\mathrm{CO}-\mathrm{Hb}$ reached $40 \%$. However, there was no evidence that a small concentration of $\mathrm{CO}-\mathrm{Hb}$ in the blood would not affect electrocardiographic findings. $\mathrm{CO}$ is generated by incomplete combustion which occurs in automobile exhaust, in industrial effluent, in household heating, and in cigarette smoke. Habitual smoking is one of the coronary risk factors. The Framingham and Albany studies ${ }^{2 / 4)}$ concluded that the mortality rate related to myocardial infarction and coronary heart disease of the heavy cigarette smoker was 3 times that of the nonsmoker. Recent smokers had higher peak creatine phosphokinase levels than either former smokers or nonsmokers, and it appears that infarctions are larger in recent smokers. ${ }^{5}$ )

Ischemic ST segment depression occurred in 3 of 10 patients with classical exertional angina pectoris while breathing freeway air. ${ }^{6}$. Becker et al ${ }^{7)}$ suggested from their animal experiment that low levels of CO-Hb may be harmful to patients with acute myocardial infarction. Goldsmith and Landaw ${ }^{8)}$ reported a relation between atmospheric $\mathrm{CO}$ and the fatality rates from myocardial infarction in Los Angeles. Although $\mathrm{CO}-\mathrm{Hb}$ blood level may be $0.4-0.8 \%$ for nonsmokers it rises to about $10-15 \%$ for heavy smokers (more than 30 cigarettes/day). ${ }^{2,3), 9)}$ The question may be posed as to whether the severity and size of myocardial infarctions are increased when the CO-Hb blood level seen in a heavy smoker is maintained.

We have studied the effects of a low concentration of CO-Hb on the electrocardiographic changes following experimental coronary ligation in dogs.

\section{Methods}

Experiments were carried out on 10 dogs $(10-15 \mathrm{Kg})$ anesthetized with sodium pentobarbital $(35 \mathrm{mg} / \mathrm{Kg}$, iv). Respiration was maintained with a Harvard respirator. The heart was exposed through a midsternal incision and suspended in a pericardial cradle. A branch of the left anterior descending coronary artery (LAD) was intermittently ligated with two silkwarmgut ligatures. Arterial pressure in the femoral artery was monitored with a Statham transducer.

Six sites on the anterior surface of the left ventricle were selected for epicardial electrogram (EG), one peripheral to the ischemic area and the others on the ischemic area from the center to the periphery (Fig. 1). A standard lead II electrocardiogram (ECG) was recorded, and the epicardial electrograms were taken with unipolar silver electrodes $1 \mathrm{~mm}$ in diameter mounted in plastic disks sutured to the epicardium. ECG and EG were monitored simultaneously with a cathode ray oscilloscope. 

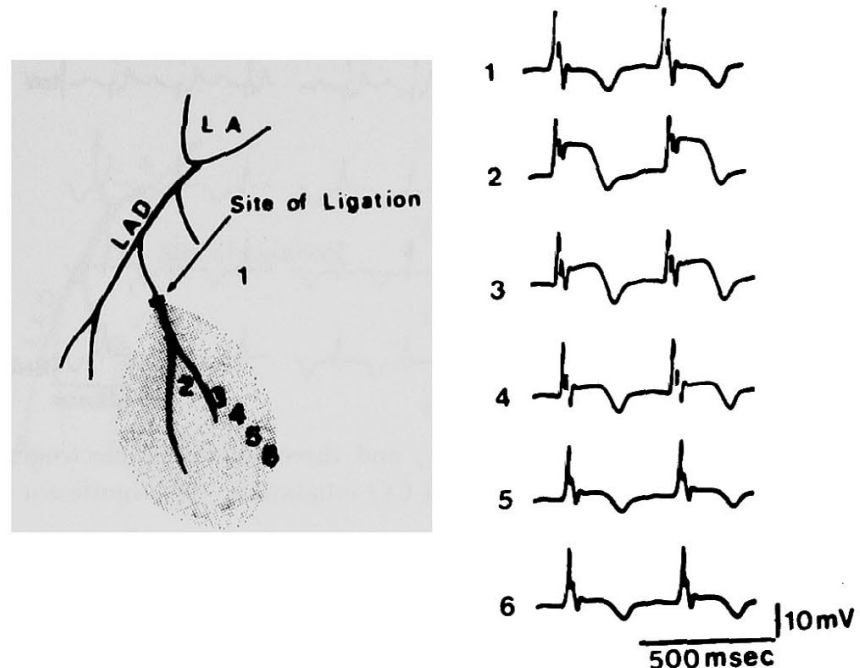

Fig. 1. Left panel: Schematic representation of the anterior surface of the heart in a dog, the left anterior descending coronary artery (LAD) and its branches, and sites of epicardial electrode placement ( 1 through 6 ). LA $=$ left atrial appendage. The shaded area represents the area of injury after 15 min of ligation. Right panel: epicardial electrograms from sites 1 through 6 after $15 \mathrm{~min}$ of ligation under room air respiration.

Inspired gas was furnished from 2 bags (one filled with a 3,000 ppm $\mathrm{CO}$ and air mixture, the other with a $130 \mathrm{ppm} \mathrm{CO}$ and air mixture connected to the respirator input. The expired gas was not returned to the bags. A $\mathrm{CO}-\mathrm{Hb}$ blood level concentration range of $13-15 \%$ was maintained by administering air with 3,000 ppm CO for the first $15 \mathrm{~min}$, and then air containing $130 \mathrm{ppm} \mathrm{CO}$ for $1 \mathrm{hr}$. The CO in the expired air was measured by controlled potential electrolysis (CO tester EG-231: Riken Keiki Co) every 15 min and $\mathrm{CO}-\mathrm{Hb}$ concentration in the blood was estimated by the following equation: $\mathrm{CO}-\mathrm{Hb}(\%)=0.085+0.172 \times \mathrm{CO}$ in expired air (ppm). ${ }^{101}$

The coronary artery was ligated 3 times in each of 10 dogs. The first ligation was maintained for $15 \mathrm{~min}$ with room air respiration, and then released. One hour following the release of the first ligation $\mathrm{CO}$ inhalation was begun and 15 min after the start of $\mathrm{CO}$ inhalation, the second ligation was performed and maintained for $15 \mathrm{~min}$ and then released under $\mathrm{CO}$ inhalation. The third 15 min ligation was begun at the time that the $\mathrm{CO}-\mathrm{Hb}$ blood level indicated $0 \%$ as determined by above equation with room air respiration.

Epicardial electrograms were obtained from the same sites throughout the experiments and were recorded before ligation and 1, 3, 5, 10, and $15 \mathrm{~min}$ after ligation without and with $\mathrm{CO}$ inhalation. The $\mathrm{CO}-\mathrm{Hb}$ concentration in the blood was obtained before $\mathrm{CO}$ inhalation and at 15, 30, 45, and $60 \mathrm{~min}$ 


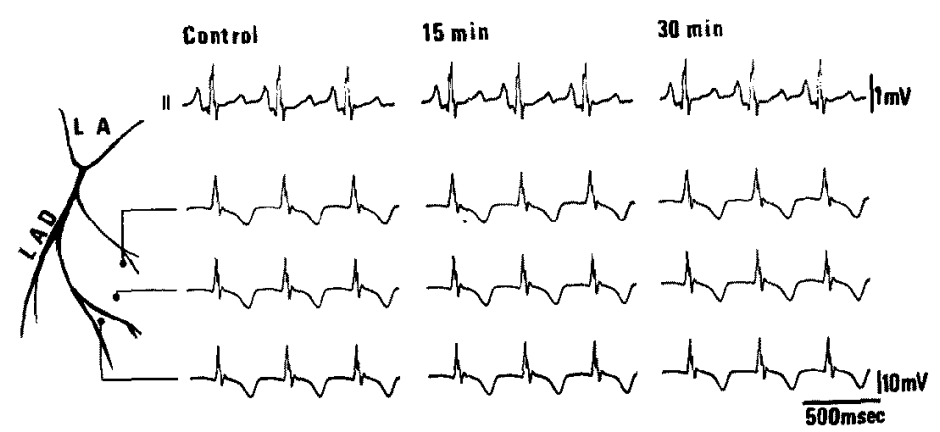

Fig. 2. Electrocardiogram (lcad II) and three epicardial electrograms before (control), $15 \mathrm{~min}$, and $30 \mathrm{~min}$ after $\mathrm{CO}$ inhalation. No significant differences appear.

during the $\mathrm{CO}$ inhalation.

Data were analysed in the following way. Epicardial ST segment elevation at each site was measured in millivolts $(1 \mathrm{mV}=1 \mathrm{~mm}$ ST segment elevation). ST segment elevation exceeding $2 \mathrm{mV}$ was considered abnormal, showing myocardial ischemic injury. In each animal, the values of the ST segment elevation from the 6 recording sites were added ( $\Sigma \mathrm{ST}$ ). This was used as the overall index to determine the severity of myocardial ischemic injury. ${ }^{11), 12) ~} \Sigma \mathrm{ST} 15 \mathrm{~min}$ after the ligation under room air respiration were used as controls. $\Sigma$ ST of the controls were compared to $\Sigma$ ST obtained at 15 min after the ligation under $\mathrm{CO}$ inhalation.

\section{Results}

In almost all experiments no significant electrocardiographic changes were observed during the inhalation of the $\mathrm{CO}$ concentration used in our study, compared with room air respiration. In some cases, the heart rate was slightly increased for a few minutes after the start of $\mathrm{CO}$ inhalation. In the absence of coronary ligation, the inhalation of $\mathrm{CO}$ which raised $\mathrm{CO}-\mathrm{Hb}$ blood levels to $14-15 \%$, did not have any influence on EGG and ventricular EGs (Fig. 2).

After a coronary artery was ligated, the area supplied by the ligated artery became cyanotic and bulged during systole in almost all experiments. Tracings made after $15 \mathrm{~min}$ of the initial ligation of a branch of LAD under room air respiration are shown in Fig. 3A. EG-1, which was outside of the ischemic area, showed no change in ST segment, while recordings from EG2 through EG-6, which were located inside the area of perfusion of the ligated artery, showed various degrees of ST segment elevation.

Fig. 4 illustrates the results from the same $\operatorname{dog}$ as in Fig. 3. $\Sigma \mathrm{ST}$ after $15 \mathrm{~min}$ of the first ligation increased from a control value of $3.3 \mathrm{mV}$ to 


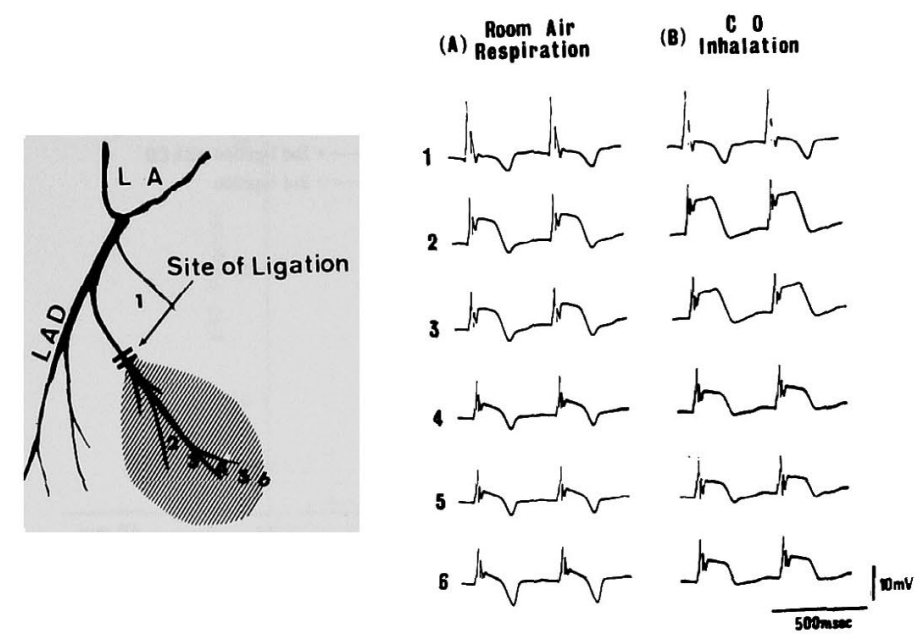

Fig. 3. Six epicardial electrograms recorded in 1 subject after 15 min of ligation. (A): first ligation under room air respiration. (B): second ligation under $\mathrm{CO}$ inhalation.

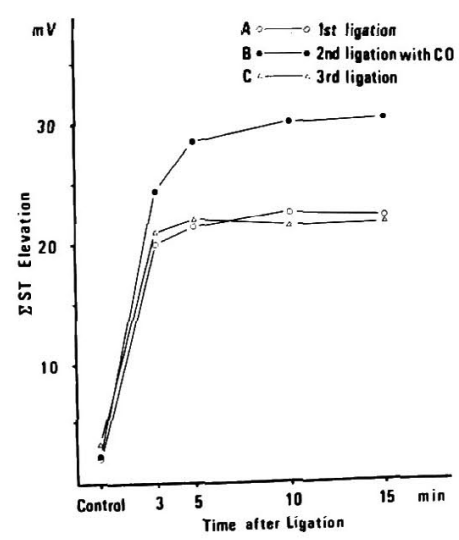

Fig. 4. $\Sigma \mathrm{ST}$ elevation in 1 subject during first ligation under room air respiration (A), during second ligation under $\mathrm{CO}$ inhalation (B), and during third ligation under room air respiration (C).

\section{$22.6 \mathrm{mV}$.}

After release of the ligation, the ST segment returned to the isoelectric line and $\Sigma \mathrm{ST}$ returned to the control value within $30 \mathrm{~min}$ (Fig. 5).

One hour after the release of the first ligation, $\mathrm{CO}$ inhalation was started. After a stable CO-Hb blood level (after 15 min of CO inhalation) was obtained, the second coronary artery ligation was repeated while $\mathrm{CO}$ inhalation was continued. In each animal, the degree of ST segment elevation seen at the sites of severe myocardial ischemia increased more than that observed in 


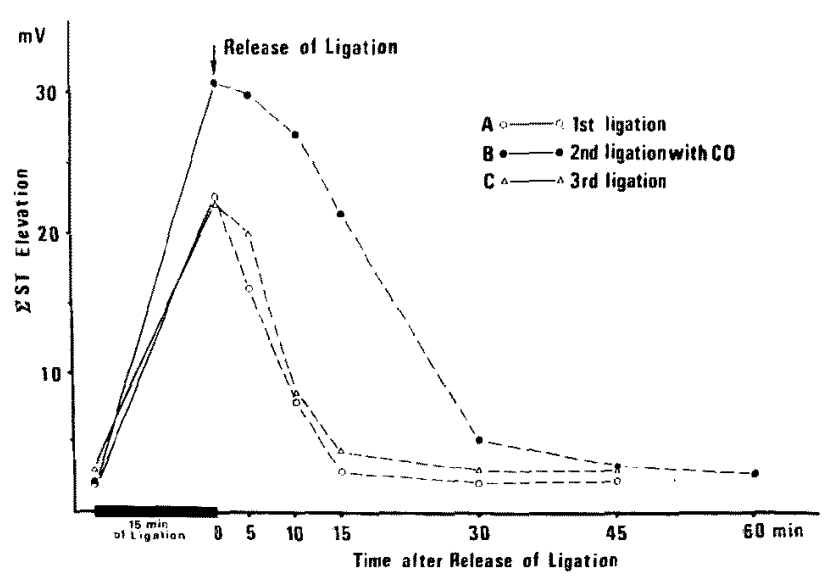

Fig. 5. ¿ST elevation recovery to normal in 1 subject after first ligation during room air respiration (A) and after second ligation during $\mathrm{CO}$ inhalation (B).

the first ligation under room air respiration (Fig. 3B). On EG-2 and EG-3, the differences in the magnitude of ST segment elevation between the first ligation with room air respiration and the second ligation with $\mathrm{CO}$ inhalation were not significant; from EG-4 to EG-6, however, the magnitude of ST segment elevation in the second ligation under $\mathrm{CO}$ inhalation significantly increased.

$\Sigma \mathrm{ST}$ in the second ligation as shown in Fig. 4 increased more rapidly than that observed in the first ligation under room air respiration and increased from a control value of $3.1 \mathrm{mV}$ before ligation to $30.8 \mathrm{mV} 15 \mathrm{~min}$ after the second ligation.

The sequence of the recovery of $\Sigma \mathrm{ST}$ is shown in Fig. 5. $\quad \Sigma$ ST returned to the control value after release of $15 \mathrm{~min}$ ligation in both cases whether under room air or $\mathrm{CO}$ inhalation, but in the case of $\mathrm{CO}$ inhalation the recovery time was increased compared with room air respiration, and this tendency was observed in all experiments.

The changes in $\Sigma \mathrm{ST}$ from the first ligation under room air respiration to the second ligation under $\mathrm{CO}$ inhalation is summarized for all 10 days in Fig. 6. $\Sigma S T$ during the first ligation with room air respiration increased from a control value of $2.06 \pm 0.34 \mathrm{mV}$ (SEM) before ligation to $24.89 \pm 2.14 \mathrm{mV}$ (SEM) after $15 \mathrm{~min}$ of ligation, while $\Sigma \mathrm{ST}$ during the second ligation with CO inhalation increased from a control value of $2.03 \pm 0.33 \mathrm{mV}$ (SEM) to $29.72 \pm$ $3.16 \mathrm{mV}$ (SEM) after $15 \mathrm{~min}$ of ligation. CO inhalation significantly increased the $\Sigma \mathrm{ST}$ compared to room air respiration $(\mathrm{p}<0.01)$.

Table I shows the degree of ST segment elevation in 6 recording sites after 15 min of ligation. The amplitudes of ST segment elevation increased 


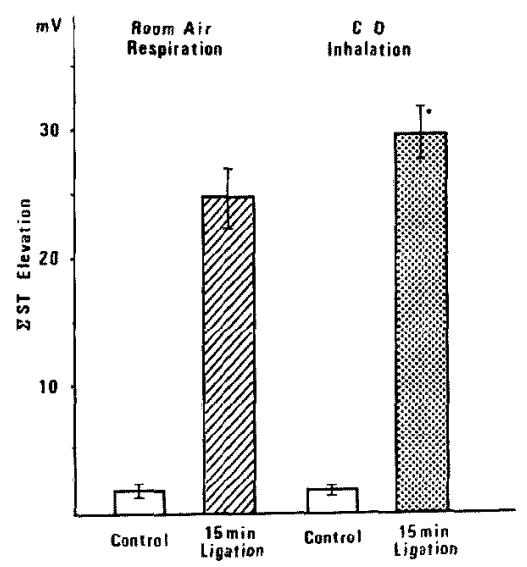

Fig. 6. Summary of the results $(10 \mathrm{dogs})$. Comparison between $\Sigma \mathrm{ST}$ elevation following $15 \mathrm{~min}$ of ligation under room air respiration and that under CO inhalation. $* p<0.01$ : first ligation under room air respiration vs second ligation under $\mathrm{CO}$ inhalation.

Table I. ST Segment Elevation of 6 Recording Sites after 15 Min of the First Ligation under Room Air Respiration and 15 Min of the Second Ligation under CO Inhalation

\begin{tabular}{l|c|c|c|c|c|c}
\hline & EG-1 & EG-2 & EG-3 & EG-4 & EG-5 & EG-6 \\
\hline 1st ligation & $0.54 \pm 0.52$ & $7.98 \pm 0.74$ & $7.58 \pm 0.82$ & $4.66 \pm 1.24$ & $2.55 \pm 0.43$ & $1.58 \pm 0.86$ \\
2nd ligation & $0.53 \pm 0.53$ & $8.18 \pm 0.80$ & $7.88 \pm 0.89$ & $6.59 \pm 0.63$ & $4.07 \pm 1.05$ & $2.60 \pm 1.14$ \\
p value* & NS & NS & NS & $\mathrm{p}<0.01$ & $\mathrm{p}<0.01$ & $\mathrm{p}<0.05$
\end{tabular}

Results are expressed mean \pm SEM of 10 subjects.

* Represents statistical significance of difference (1st ligation vs 2nd ligation).

$\mathrm{NS}=$ not signific ance.

significantly during the second ligation with $\mathrm{CO}$ inhalation, as compared to the value recorded during the first ligation with room air respiration on EG-4 $(p<0.01)$, EG-5 $(p<0.01)$, and EG-6 $(p<0.05)$, but were not significantly different on EG-2 and EG-3.

In 7 dogs $\Sigma$ ST elevation during the third ligation with room air respiration showed similar increases in $\Sigma S T$ elevation as were seen during the first ligation (Fig. 4C), and increased from $1.97 \pm 0.30 \mathrm{mV}$ (SEM) before ligation to $25.28 \pm 2.62 \mathrm{mV}(\mathrm{SEM})$ after $15 \mathrm{~min}$ of ligation. These results suggest that inhalation of low concentrations of $\mathrm{CO}$ in this experimental condition did not appear to produce irreversible damage to the myocardium. 


\section{Discussion}

Cigarette smoking is one of the major risk factors contributing to coronary heart disease, and increases the risk of developing coronary heart disease in the presence of hypertension and hypercholestrolemia. ${ }^{3)}$ Additionally, it has been reported that severe aortic and coronary artery atherosclerosis was present in a higher percentage of heavy smokers compared to nonsmokers. ${ }^{13)}$ Folts and Bonebrake noted that cigarette smoking contributed to the development of an acute occlusive platelet thrombus in a stenotic coronary artery. ${ }^{14)}$ Meanwhile, nicotine and $\mathrm{CO}$ are absorbed in the blood of cigarette smokers. Nicotine may increase cathecholamine release from the adrenergic axon terminal within the cardiovascular system, ${ }^{15}$ ) enhancing myocardial oxygen demand. Since CO has a 245-fold greater affinity for hemoglobin in comparison with that of oxygen, myocardial oxygen availability might be reduced in heavy smokers. Other authors reported that either nicotine or $\mathrm{CO}$ increased thrombotic tendency, ${ }^{16), 13)}$ and reduced the ventricular fibrillation threshold during myocardial ischemia. ${ }^{18)-20\}}$

There are several reports ${ }^{21)-24)}$ on the morphological changes in the cardiovascular system caused by light chronic carbon monoxide exposure, but only a few reports on the electrocardiographic changes and the $\mathrm{CO}-\mathrm{Hb}$ blood level. Acute carbon monoxide poisoning in humans or animals leads to electrocardiographic abnormalities and the development of arrhythmias. No objective signs were noted in dogs which were exposed to $\mathrm{CO}$ for 14 weeks, with a $\mathrm{CO}-\mathrm{Hb}$ blood level of $14 \% .{ }^{25}$ ) There was evidence of impending cardiac depression beginning at blood levels of $20 \% \mathrm{CO}-\mathrm{Hb}^{26}$ ) As seen in the canine studies, with sudden elevation of $\mathrm{CO}-\mathrm{Hb}$ concentration to $25 \%$, coronary blood flow almost doubled without significant increases in cardiac output, femoral arterial pressure and heart rate, and the canine myocardium became hypoxic and showed evidence of anerobic metabolism when $\mathrm{CO}-\mathrm{Hb}$ levels were acutely raised to $20-30 \% .{ }^{27)}$ Our study suggested that myocardial function would be maintained in a normal state at $\mathrm{CO}-\mathrm{Hb}$ concentration level ranging from $13-15 \%$. This concentration of $\mathrm{CO}-\mathrm{Hb}$ had little influence on the balance between myocardial oxygen supply and demand in the normal state because there were no changes in heart rate, or femoral artery pressure, and the epicardial electrogram did not show any ST segment abnormality. But when the coronary artery ligation was performed during CO inhalation, the area of ischemic injury and the magnitude of ST segment clevation were increased compared with that without $\mathrm{CO}$ inhalation. The present study may suggest that a low concentration of $\mathrm{CO}-\mathrm{Hb}$ may increase the extent of myocardial ischemic injury. Inhalation of $\mathrm{CO}$ deprives the oxygen trans- 
port function to the myocardium not only of hemoglobin but also of myoglobin. Myoglobin has a higher affinity for $\mathrm{CO}$ than does hemoglobin, and myoglobin is saturated with $\mathrm{CO}$ concentrations approximately 2 or 3 times higher than the $\mathrm{CO}-\mathrm{Hb}$ concentration seen at relatively low $\mathrm{CO}-\mathrm{Hb}$ levels. ${ }^{24}$ ) Because of the displacement to the left of the oxygen dissociation curve of hemoglobin and myoglobin, the myocardial oxygen tension was decreased. The peripheral part of the ischemic area received oxygen from the ligated artery and the collateral artery. The latter is responsible for the progressive diminution of the size of the ischemic area seen in the case without $\mathrm{CO}$ inhalation, but this collateral circulation did not increase at the same rate during $\mathrm{CO}$ because of the effects of $\mathrm{CO}-\mathrm{Hb}$ on blood flow. This was further verified by Sayen et al ${ }^{28), 29)}$ who noted a close correlation between the area of ST segment elevation and the reduction of myocardial oxygen tension. The evidence for this is based on Fig. 5 which shows that after release of ligation the time to recover to the normal state in the case under $\mathrm{CO}$ inhalation was much longer than that without $\mathrm{CO}$ inhalation.

\section{REFERENCES}

1. Takahashi K: Cardiac disturbances due to $\mathrm{CO}$ poisoning in experimental animals, I. Electrocardiographic changes duc to $\mathrm{CO}$ poisoning and those under the influences of fluid infusion. Tohoku J Exp Med 74: 211, 1961

2. Doyle JT, Dawber TR, Kannel WB, Heslin AS, Kahn HA: Cigarette smoking and coronary heart disease combined Experience of the Albany and Framingham Studies. New Engl J Med 266: 796, 1962

3. Doyle JT, Dawber TR, Kannel WB, Kinch SH, Kahn HA: The relationship of cigarette smoking to coronary heart disease. JAMA 190: 886, 1964

4. Gordon T, Kannel WB, McGeed, Dawber TR: Death and coronary attacks in men after giving up cigarette smoking. Lancet II: 1345,1974

5. Weisfeldt M, Radford E, Tucker M, Greene L, Flaherty J, Becker L, Taylor D, Kelly D, Pitt B, Steinberg E, Martin L: Peak creatine phosphokinase and hemodynamics in smokers with acute myocardial infarction. Circulation 52 (Suppl): II-256, 1975

6. Aronow WS, Harris CN, Isbell MW, Rokaw SN, Imparato B: Effect of freeway travel on angina pectoris. Ann Int Med 77: 669, 1972

7. Becker LC, Haak ED: Augmentation of myocardial ischemia by low level carbon monoxide exposure in dogs. Arch Environ Health 34: 247, 1979

8. Goldsmith JR, Landaw SA: Carbon monoxide and human health. Science 162: 1352, 1968

9. WHO: Health hazards of the human environment. World Health Organization, p 194, 1972

10. Sato J, Maeda H, Nago M, Kubota T, Muroya H: Studies of the determination of COHb in blood. Jpn J Hyg 29: 104, 1974 (in Japanese)

11. Maroko PR, Kiekshus JK, Sobel BE, Watanabe T, Covell JW, Ross J Jr, Braunwald E: Factors infuencing infarct size following experimental coronary artery occlusion. Circulation 43: 67,1971

12. Maroko PR, Libby P, Covell JW, Sobel BE, Ross J Jr, Braunwald E: Precordial S-T segment elevation mapping. An atraumatic method for assessing alterations in the extent of myo- 
cardial ischemic injury. Am J Cardiol 29: 223, 1972

13. Strong JP, Richards ML: Cigarette smoking and atherosclerosis in autopsied men. Atherosclerosis $23: 451,1976$

14. Folts JD, Bonebrake BS: The effects of cigarette smoke and nicotine on platelet thrombus formation in stenosed dog coronary arteries: inhibition with phentolamine. Circulation 65 : 465,1982

15. Cryer PE, Haymond MW, Santiago JV, Shah SD: Norepinephrine and epinephrine release and adrenergic mediation of smoking-associated hemodynamic and metabolic events. New Engl J Med 295: 573, 1976

16. Levine PH: An acute effect of cigarette smoking on platelet function. A possible link between smoking and arterial thrombosis. Circulation 48:619, 1973

17. Birnstingl MA, Brinson $\mathrm{K}$, Chakrabarti $\mathrm{BK}$ : The effect of short-term exposure to carbon monoxide on platelet stickiness. Br J Surg 58: 837, 1971

18. Bellet S, DeGuzman NT, Kostis JB, Roman L, Fleischmann D: The effect of inhalation of cigarette smoke on ventricular fibrillation threshold in normal dogs and dogs with acute myocardial infarction. Am Heart J 83: 67, 1972

19. DeBias DA, Banerjce CM, Birkhead NC, Greene CH, Scott SD, Harrer WV: Effects of carbon monoxide inhalation on ventricular fibrillation. Arch Environ Health 31: 42, 1976

20. Aronow WS, Stemmer EA, Wood B, Zweig S, Tsao K, Raggio L: Carbon monoxide and ventricular fibrillation threshold in dogs with acute myocardial injury. Am Heart J 95: 754, 1978

21. Astrup P, Kjeldsen K, Wanstrup J: Enhancing influence of carbon monoxide on the development of atheromatosis in cholesterol fed rabbits. Atherosclerosis 7: 343, 1967

22. Webster WX, Clarkson TB, Lofland HB: Carbon monoxide-aggravated atherosclerosis in the squirrel monkey. Exp Mol Pathol 13: 36, 1970

23. Kjeldsen $\mathrm{K}$, Astrup P, Wanstrup J: Ultrastructural intimal changes in the rabbit aorta after a moderate carbon monoxide exposure. Atherosclerosis 16: 67, 1972

24. Kjeldsen K, Thomsen HK, Astrup P: Effects of carbon monoxide on myocardium. Ultrastructural changes in rabbits after moderate, chronic exposure. Circulat Res 34: 339, 1974

25. DeBias DA, Birkhead NG, Banerjee CM, Kazal LA, Holburn RP, Greene CH, Harrer WV, Rosenfeld LM, Menduke H, William N, Friendman MHF: The effects of chronic exposure to carbon monoxide on the cardiovascular and hematologic systems in dogs with experimental myocardial infarction. Int Arch Arbeitsmed 29: 253, 1972

26. Gramlet SH, Erickson HH, Gorman HA: Ventricular function following acute carbon monoxide exposure. J Appl Physiol 39: 482, 1975

27. Ayres SM, Giannelli S Jr, Mueller $\mathrm{H}$ : Myocardial and systemic responses to carboxyhemoglobin. Ann NY Acad Sci 174: 268, 1970

28. Sayen JJ, Sheldon WF, Peirce G, Kuo PT: Polarographic oxygen, the epicardial electrocardiogram and muscle contraction in experimental acute regional ischemia of the left ventricle. Circulat Res 6: 779, 1958

29. Sayen JJ, Katcher AH, Sheldon WF, Gilbert CM: The effect of levarterenol on polarographic myocardial oxygen, the epicardial electrocardiogram and contraction in nonischemic dog hearts and experimental acute regional ischemia. Circulat Res 8: 109, 1960 